\title{
Modelling microbial fuel cells with suspended cells and added electron transfer mediator
}

\author{
Cristian Picioreanu - Krishna P. Katuri • \\ Mark C. M. van Loosdrecht · Ian M. Head • \\ Keith Scott
}

Received: 12 March 2009/ Accepted: 16 August 2009/Published online: 12 September 2009

(C) Springer Science+Business Media B.V. 2009

\begin{abstract}
Derivation of a mathematical model for microbial fuel cells (MFC) with suspended biomass and added electron-transfer mediator is described. The model is based on mass balances for several dissolved chemical species such as substrate, oxidized mediator and reduced mediator. Biological, chemical and electrochemical reactions can occur in the bulk liquid and at the electrode surface, respectively. Model outputs include time-dependent production of current and electrical charge, current-voltage and current-power curves, and the evolution of concentrations of chemical species. The model behaviour is illustrated using a test case based on detailed experimental observations reported in the literature for a microbial fuel cell operated in batch mode and repeatedly fed with a single substrate. A detailed model parameter estimation procedure is presented. The model simulates the current-time evolution and voltage-current curves in the MFC with glucose as anode substrate and the ferrocyanide/ferricyanide redox couple as the
\end{abstract}

C. Picioreanu - M. C. M. van Loosdrecht

Department of Biotechnology, Faculty of Applied Sciences, Delft University of Technology, Julianalaan 67, 2628 BC Delft,

The Netherlands

e-mail: C.Picioreanu@tudelft.nl

K. P. Katuri · K. Scott ( $\bowtie)$

School of Chemical Engineering and Advanced Materials, University of Newcastle Upon Tyne, Merz Court,

Newcastle Upon Tyne, Tyne and Wear NE1 7RU, UK

e-mail: k.scott@ncl.ac.uk; K.Scott@newcastle.ac.uk

K. P. Katuri

e-mail: K.P.Katuri@ncl.ac.uk

I. M. Head

School of Civil Engineering and Geosciences,

University of Newcastle Upon Tyne, Devonshire Building,

Newcastle Upon Tyne, Tyne and Wear NE1 7RU, UK

e-mail: i.m.head@ncl.ac.uk oxidation reaction at the cathode. Simulations show the effect of different parameters (electrical resistance, mass transfer resistance, exchange current, coulombic yields and biomass, substrate and mediator concentrations) on the MFC characteristics. The model explains how the endogenous metabolism or intracellular substrate storage could lead to a non-zero background current even when the added substrate has been depleted. Different trends (increasing or decreasing) in the initial current are explained by the initial oxidation state of the mediator (oxidized or reduced, respectively). The model has potential applications for other bioelectrochemical systems.

Keywords Microbial fuel cell - Mathematical model . Electron-transfer mediator

\section{Introduction}

Microbial fuel cells (MFCs) are a type of fuel cell that convert the chemical energy contained in organic matter to electricity using bacteria as a biocatalyst. In MFCs, bacteria do not transfer their electrons directly to their characteristic terminal electron acceptor, but rather to a solid electrode [19]. The interest in MFC is increasing mainly because they offer the possibility of directly harvesting electricity from organic waste and renewable biomass [13]. The potential advantages of biological systems over the conventional chemical systems have been described previously [10]. Firstly, it is feasible to develop MFCs that can operate under very mild conditions. Secondly, any biodegradable material that can be oxidized by the microorganisms can serve as fuel. The conversion of waste materials (e.g., agricultural residues) into electrical energy is also possible and, of course, a very attractive option. 
A number of recent reviews dedicated both to the understanding of the microbiology of MFC processes [4, 13, $23]$ and to advances in the technological aspects [3, 10, 12, $19,20]$ outline the design configurations for MFCs. In an integrated fermentation $M F C$, fermentation of organic substrates takes place directly in the anodic compartment of a fuel cell, supplying the anode with the fermentation products generated in situ. A mediated $M F C$ involves electron transfer mediators that can shuttle electrons between the microbial biocatalytic system and the electrode [21]. The biocatalytic process differs from the natural situation because electron flow goes to the anode instead of to a natural electron acceptor. Because $\mathrm{O}_{2}$ as a natural electron acceptor is usually a more efficient oxidant than the anode, the MFC anode compartment is operated under anaerobic conditions. Overall, the biomass in these MFCs is a combination of cells in suspension and biofilm attached to the electrode. The third and the newest approach is MFC in which direct electron transfer to the anode occurs. A number of bacteria have been found to transfer electrons from reduced substrates to a working electrode without a soluble mediator (for mediator-less MFCs see the review by [4].

Although MFCs promise sustainable energy generation in the future, many bottlenecks still exist. This challenge needs a multidisciplinary approach [19], because multiple physical, chemical and biological factors interact and play a role in dictating the final MFC performance. The extractable power of a fuel cell is affected by the difference in the potentials of the oxidizer and fuel compounds, irreversible losses due to kinetic limitations of the electron transfer processes at the electrode interfaces, ohmic resistances and concentration gradients, the electrode sizes and transport rates across the membrane separating the MFC compartments. Identification of rate-limiting steps allows development of strategies to enhance the MFC output. Substantial knowledge already exists from traditional chemical fuel cells on mass transfer, reactions and electrical phenomena, and this can be also adapted to MFCs. However, the mechanisms for electron transfer from cells to electrode and the microbiology of MFCs are less well understood. Many theories have been proposed but the validity of several hypotheses on electron transfer mechanisms remains to be tested.

The rigour of mathematical modelling provides a framework for testing hypothesis and a method to integrate information gathered from several disciplines and by researchers with backgrounds ranging from biology to engineering. With the exception of one case over a decade ago [26], there have been, until very recently, no modelling studies dedicated to microbial fuel cells [9, 15]. Zhang and Halme's preliminary work attempted to simulate the currents produced by MFC with suspended cells and an added mediator only. The models of Picioreanu et al. and KatoMarkus et al. are dedicated to biofilm-based MFC, the configuration most studied experimentally nowadays by microbiologists and engineers. However, a considerable drawback of these biofilm-based models for use in practical applications is their inherent complexity. In comparison to other relevant published models, the simplicity of the present model may easily serve as a basis for more complex systems to be modelled. This should encourage other researchers in the field to model their own systems.

We believe that the development of mathematical models in general (and of MFC, in particular) should be based on proven mechanisms and on relatively well-established concepts and systems. Although microbial fuel cells with suspended cells and added mediator are inefficient devices to produce cheaper electricity, their simplicity allows experimentation under well-controlled conditions. Many of the parameters (e.g., electrode kinetics, microbial stoichiometry and kinetics, electrical parameters) needed for characterization of more complex devices such as the biofilm-based MFCs, can be still determined in this simple setup. A wealth of data is already available in the literature, which allows direct model validation. In a first attempt of its kind, this study has the main goal of laying the basis of a simple mathematical model that accurately describes MFC behaviour with suspended cells and electron transfer from microbial cells to the anode via a diffusible mediator. In this model we describe in detail only the dynamic behaviour of the anodic compartment, having in mind that a description of the cathodic chamber can follow the same approach. The model will be used to interpret experimental data obtained by Bennetto's group on MFCs with added soluble mediator (thionine) and suspended Proteus cells [5, 21, 24]. Such a model is also useful because it points to parameters that still need to be measured. The introduction of mediators in an MFC is one way of potentially extracting more power out of microbial cells by coupling their redox behaviour with mediators produced by micro-organisms. Including other electron transfer mechanisms such as by direct contact [4] or connection to the anode via proposed conducting structures termed "nano-wires" (Reguera et al. 2005) in the model framework is possible, and shall be presented in further studies. Parameters obtained in this study were used in the evaluation of more complex MFC models including biofilms, recently presented by Picioreanu et al. [15] and Picioreanu et al. [17]. Moreover, this simple model can be used with minimal changes also for other bioelectrochemical systems (BES), as well as MFCs. An example where this model could be applied is the recently reported bioelectrochemical glycerol conversion into ethanol and hydrogen in a similar setup with suspended cells and thionine as redox mediator [22]. 


\section{Methods}

\subsection{Experimental}

This modelling study is based on the detailed experimental observations by Bennetto's group in the 1980s [5, 21, 24] and Kim's work in the late 1990s [11]. For convenience, their experimental setup is briefly described here. The MFC had two compartments separated by a cation-permeable ionexchange membrane. The anode and cathode chambers were assembled together in a back-to-back fashion, like in stacked fuel cells. The anode was made of reticulated vitrous carbon and the cathode was a platinum foil. The two half-cells were sparged with $\mathrm{N}_{2}$ to mix and to remove the oxygen. The anolyte was a solution of electron transfer mediator (e.g., thionine) and glucose buffered with phosphate to $\mathrm{pH} 7$. For the catholyte, a ferricyanide solution in phosphate buffer $(\mathrm{pH} 7)$ was used for stable polarization. Freshly prepared microorganisms suspended in phosphate buffer were added in defined amounts. The assembled MFCs were placed in a water bath at $30{ }^{\circ} \mathrm{C}$. Current-time curves were obtained from the dependence in time of the cell voltage at a fixed resistive load.

\subsection{Model development}

The computational model of MFC is constructed with the aim to reproduce the short-term (i.e., hours) current production when the MFC is discharged through a resistor after the addition of substrate and mediator. The procedure developed in this case is directly applicable also to enzymatic fuel cells using soluble mediators and dissolved enzyme.

\subsubsection{Computational domains}

Two spatial compartments are defined for this model: the bulk liquid in the anode chamber and the mass transfer boundary layer adjacent to the anode. A schematic representation of the model is presented in Fig. 1. The bulk liquid of volume $V_{\mathrm{B}}$ is
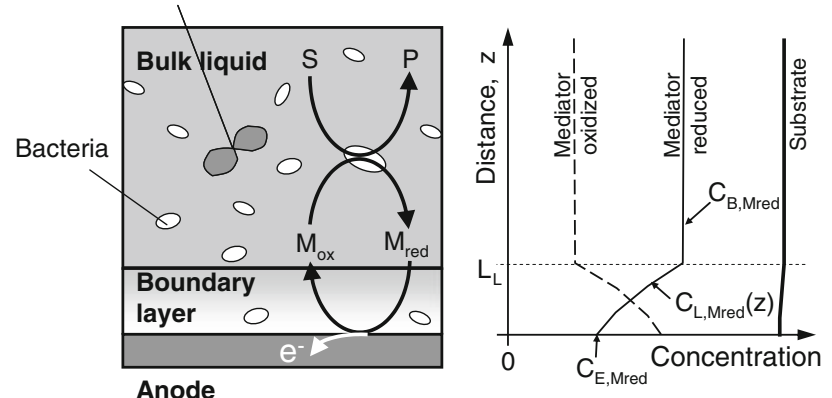

Fig. 1 Schematic representation of the model for the anodic compartment of a MFC with suspended cells and dissolved diffusible redox mediator. Concentration of reduced mediator falls across the diffusion boundary layer, whereas the oxidized mediator is produced at the anode and its concentration symmetrically increases assumed to be completely mixed and to contain suspended biomass in active state. Batch operation of the MFC is simulated (experiments by Kim et al. [11], Thurston et al. [24]. Alternatively, repeated substrate addition in a fed-batch mode is also considered (experiments by [5]. Soluble components diffuse between the bulk liquid and the electrode through a mass transfer boundary layer (MTBL) of thickness, $L_{\mathrm{L}}$, adjacent to the anode. To simplify the approach, a planar electrode surface of area $A_{\mathrm{E}}$ is chosen here as example.

\subsubsection{Components and reactions}

We assume a simple reaction scheme (Eqs. 1-2) of mediated substrate oxidation. There is only one reaction in the bulk liquid, in which an organic substrate $S$ is oxidized by suspended cells using the mediator in an oxidized state, $M_{\mathrm{ox}}$ :

$Y_{\mathrm{S}} \mathrm{S}+\mathrm{M}_{\mathrm{ox}} \rightarrow \mathrm{M}_{\mathrm{red}}+$ products

The biochemically produced reduced mediator $M_{\text {red }}$ is electrochemically oxidized at the anode:

$\mathrm{M}_{\mathrm{red}} \rightleftarrows \mathrm{M}_{\mathrm{ox}}+n \mathrm{H}^{+}+n \mathrm{e}^{-}$

The stoichiometric coefficient of the substrate in Eq. 1 depends on the electron content of that substrate. For example, if glucose is completely oxidized to $\mathrm{CO}_{2}$, this needs 24 electrons to be accepted by the mediator. If then one mol of oxidized mediator accepts two electrons (as it is the case for thionine, for example), then the theoretical yield of glucose per mediator is $Y_{\mathrm{S}}^{\max }=1 / 12=0.0833 \mathrm{~mol} \mathrm{~mol}^{-1}$. The real yield $Y_{\mathrm{S}}$ is however different because not all available electrons contained in the substrate will be transferred to the anode, i.e., the coulombic yield is $Y_{\mathrm{Q}}<1$. The coefficient $Y_{\mathrm{S}}$ remains to be determined from the current actually produced, as further shown in "Estimation of model parameters" section. Because no other growth-essential nutrients were added in the anode medium, biomass growth is not considered here. However, an estimation of biomass yields on different substrates and mediators is possible on thermodynamic grounds (see [15], based on [7]. Likewise, other possible products of reaction are not relevant for this analysis. Only three soluble components will therefore be included in this case: substrate (glucose in [5]), oxidized mediator and reduced mediator. $\mathrm{pH}$ will be considered constant (i.e., the system is well buffered, cf. [5].

The stoichiometry of electrochemical reaction (2) reflects the number of electrons transferred, $n$. Here it was assumed $n=2$ (for example, the mediator is thionine).

\subsubsection{Reaction rates}

Kinetics must be assumed for both reactions. The rate of biological reaction (1) is expressed as a double Monod limitation on substrate and $M_{\mathrm{ox}}$ concentrations: 
$r_{1}=k_{1} C_{\mathrm{X}} \frac{C_{\mathrm{S}}}{K_{\mathrm{S}}+C_{\mathrm{S}}} \frac{C_{\mathrm{Mox}}}{K_{\mathrm{Mox}}+C_{\mathrm{Mox}}}$

with $k_{1}$ the maximum rate coefficient [ $\mathrm{kmol}$ mediator $\mathrm{g}$ biomass $^{-1}$ day $^{-1}$ ], $C_{\mathrm{X}}$ the biomass concentration $\left[\mathrm{g} \mathrm{m}^{-3}\right.$, $K_{\mathrm{S}}$ and $K_{\mathrm{Mox}}$ the half-saturation (Monod) coefficients [kmol $\mathrm{m}^{-3}$ ] for substrate and oxidized mediator, respectively. As a particular case, for small concentrations (i.e., $C_{\mathrm{S}} \ll K_{\mathrm{S}}$ and $C_{\text {Mox }} \ll K_{\text {Mox }}$ ) a second order (in chemical components) reaction rate is applicable (i.e., $r_{1}=k_{1}^{*} C_{\mathrm{X}} C_{S} C_{\text {Mox }}$ ), similar to the expression experimentally found by Bennetto et al. [1]. The net rates for glucose and the two mediator forms in the bulk liquid are expressed using rate Eq. 3, reaction stoichiometry (1), and the concentrations having the values in bulk liquid, $C_{\mathrm{B}, \mathrm{S}}$ and $C_{\mathrm{B}, \mathrm{Mox}}\left[\mathrm{kmol} \mathrm{m}^{-3}\right]$ and $C_{\mathrm{X}}\left[\mathrm{g} \mathrm{m}^{-3}\right]$ :

$$
\begin{aligned}
& r_{\mathrm{B}, \mathrm{S}}=-Y_{S} r_{1}\left(C_{\mathrm{X}}, C_{\mathrm{B}, \mathrm{S}}, C_{\mathrm{B}, \mathrm{Mox}}\right), \quad r_{\mathrm{B}, \mathrm{Mred}}=r_{1}, \\
& r_{\mathrm{B}, \mathrm{Mox}}=-r_{1}
\end{aligned}
$$

The rate of the electrochemical process must also be established. The electrical current occurs when certain dissolved chemical species are oxidized on the anode and others are reduced on the cathode. The surface-based rates of electrochemical reactions occurring on the anode are expressed as a function of the current density, $i\left[\mathrm{~A} \mathrm{~m}^{-2}\right]$. The net rates for mediators conversion at the electrode $\left(\mathrm{kmol} \mathrm{m}^{-2} \mathrm{day}^{-1}\right)$ are then a function of current density, stoichiometry and the concentrations values at the electrode surface, $C_{\text {E,Mred }}$ and $C_{\text {E,Mox }} \quad\left[\mathrm{kmol} \mathrm{m}^{-3}\right]$ (Faraday's law):

$r_{\mathrm{E}, \mathrm{Mred}}=-\frac{i\left(C_{\mathrm{E}, \mathrm{Mred}}, C_{\mathrm{E}, \mathrm{Mox}}\right)}{n F}, \quad r_{\mathrm{E}, \mathrm{Mox}}=\frac{i}{n F}$

The current density produced in the electrochemical mediator oxidation (at constant $\mathrm{pH}$ ) can be expressed by the Butler-Volmer equation [14]:

$$
\begin{aligned}
i= & i_{0, \text { ref }}\left(\frac{C_{\text {E,Mred }}}{C_{\text {ref,Mred }}}\right)\left(\frac{C_{\text {E,Mox }}}{C_{\text {ref }, \text { Mox }}}\right)^{-1}\left[\exp \left(\frac{2.303}{b} \eta_{\mathrm{A}, \text { act }}\right)\right. \\
& \left.-\exp \left(-\frac{2.303}{b} \eta_{\text {A,act }}\right)\right]
\end{aligned}
$$

with parameters $b$ being the Tafel slope [V/decade of current] and the exchange current density function of the current density $i_{0 \text {,ref }}\left[\mathrm{A} \mathrm{m}^{-2}\right]$ measured at certain reference concentrations of reactants and products, $C_{\text {ref }}$. Note however that different expressions for current densities can be derived, based on the mechanism of reaction on the electrode. Therefore, the reaction orders (here, 1 for $M_{\text {red }}$ and 1 for $M_{\mathrm{ox}}$, respectively) are not necessarily the same as the stoichiometric coefficients. In order to calculate the current density according to Eq. 6, the activation overpotential $\eta_{\mathrm{A} \text {,act }}[\mathrm{V}]$ of the anodic electrochemical reaction must be known. The following paragraph explains how $\eta_{\mathrm{A} \text {,act }}$ is calculated from a potential balance over the MFC.

\subsubsection{Electrical model}

When the (microbial) fuel cell is connected with an external resistance $R_{\text {ext }}$ (also called "load", see Fig. 2), Ohm's law gives the proportionality between the microbial fuel cell voltage, $V_{\text {cell }}$, and the current $I$ flowing through the resistor: $V_{\text {cell }}=I R_{\text {ext }}$

The maximum fuel cell voltage to be ideally achieved is given by its equilibrium potential, $E_{\text {cell }}$, which is a thermodynamically imposed upper limit. However, the actual fuel cell voltage $V_{\text {cell }}$ is decreased from the equilibrium potential by a series of irreversible losses. The losses, called overpotential or polarization, originate primarily from three sources: (1) activation overpotential $\left(\eta_{\text {act }}\right.$, directly related to the rates of electrochemical reactions at the electrode surface), (2) ohmic overpotential ( $\eta_{\mathrm{ohm}}$, is the resistance to the flow of ions in the electrolyte and to flow of electrons through the electrode materials), and (3) concentration overpotential ( $\eta_{\text {conc }}$, due to the mass transfer limitations of chemical species transported to or from the electrode) [6]. All these overpotentials are by convention here positive values. By summation of all polarization losses, at anode and cathode, the cell voltage is written as:

$$
\begin{aligned}
V_{\text {cell }} & =E_{\text {cell }}-\eta_{\text {act }}-\eta_{\mathrm{ohm}} \\
& =\left(E_{\mathrm{C}}-\eta_{\mathrm{C}, \text { act }}\right)-\left(E_{\mathrm{A}}+\eta_{\mathrm{A}, \mathrm{act}}\right)-\eta_{\mathrm{ohm}}
\end{aligned}
$$

In Eq. 8, concentration overpotentials do not appear because the equilibrium potentials for the cathode and anode, $E_{\mathrm{C}}$ and $E_{\mathrm{A}}$, were directly calculated with the concentrations $C_{\mathrm{E}}$ at the electrode surface. Concentrations $C_{\mathrm{E}}$ are determined by mass transport and reaction and are variable in time. Furthermore, if both the electrolyte and fuel cell electrodes obey Ohm's law, then $\eta_{\mathrm{ohm}}=I R_{\text {int }}$, with $R_{\text {int }}$ including electronic, ionic and contact resistance.

Finally, by combining Eqs. 7 and 8 one obtains the anodic activation overpotential in which we are actually interested (see also Fig. 2):

$\eta_{\mathrm{A}, \mathrm{act}}=\left(E_{\mathrm{C}}-\eta_{\mathrm{C}, \mathrm{act}}\right)-E_{\mathrm{A}}-I\left(R_{\mathrm{int}}+R_{\mathrm{ext}}\right)$

Calculation of the anodic activation overpotential in the numerical examples studied here assumes a constant value for the cathode potential $V_{\mathrm{C}}=E_{\mathrm{C}}-\eta_{\mathrm{C} \text {,act }}$, and is thus independent of current $I$. This is for reasons of simplification (i.e., we are mainly interested here in the behaviour of the anodic chamber) and because experiments of Benetto's group used a ferricyanide cathode which exhibits small activation polarization $\eta_{\mathrm{C} \text {,act }}$ (i.e., quasi-constant $V_{\mathrm{C}}$ ).

Furthermore, a value for the equilibrium potential of anodic reaction is needed. This is function of the standard redox potential, $E_{\mathrm{A}}^{0}$, amended for the actual concentrations calculated at the electrode surface. For the anodic mediator oxidation reaction, this can be written as: 
Fig. 2 a The MFC as an electrical circuit. b The cell voltage $V_{\text {cell }}$ is what remains after potential lossesoverpotentials for anode and cathode activation, $\eta_{\mathrm{A} \text {,act }}$ and $\eta_{\mathrm{C} \text {,act }}$ and ohmic overpotential generated by the internal resistance of MFC-are subtracted from the ideal equilibrium cell potential, $E_{\mathrm{C}}-E_{\mathrm{A}}$. The cell voltage $V_{\text {cell }}$ will keep the current $I$ flowing in the external circuit of resistance $R_{\text {ext }}$

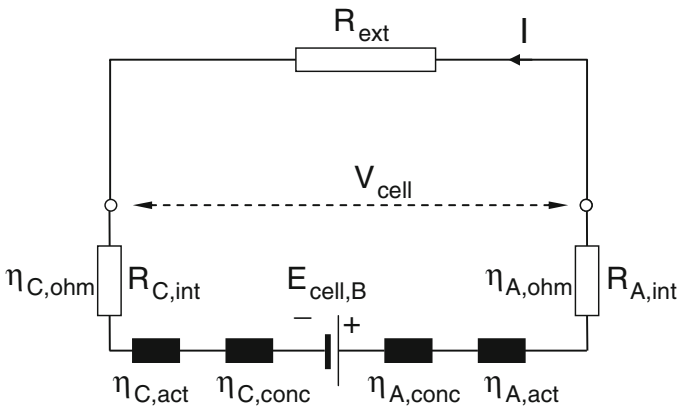

(A)

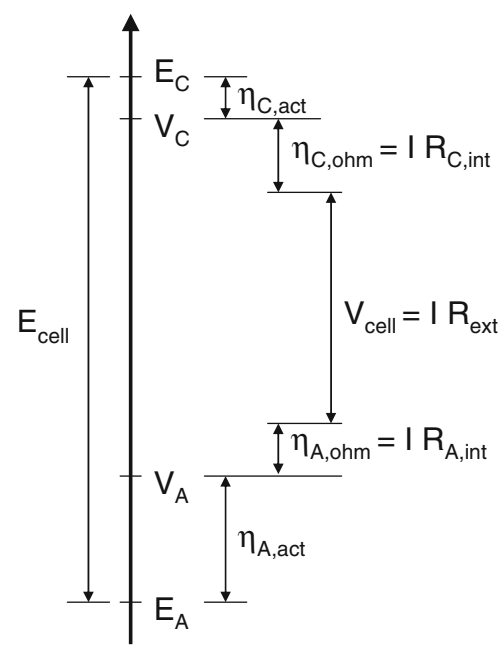

(B)
$E_{\mathrm{A}}=E_{\mathrm{Mox} / \mathrm{Mred}}^{0}+\frac{R T}{n F} \ln \frac{C_{\mathrm{E}, \mathrm{Mox}} C_{\mathrm{E}, \mathrm{H}^{+}}^{2}}{C_{\mathrm{E}, \mathrm{Mred}}}$

Finally, at constant $\mathrm{pH}$ and $30{ }^{\circ} \mathrm{C}$, with the internal and external cell resistances known, and with the reduction potential of the mediator in standard conditions, $E_{\text {Mox } / \text { Mred }}^{0}$, the activation overpotential is a function of the current $I$ passing through the fuel cell:

$$
\begin{aligned}
\eta_{\mathrm{A}, \text { act }}= & V_{\mathrm{C}}-I\left(R_{\text {int }}+R_{\text {ext }}\right) \\
& -\left(E_{\text {Mox } / \text { Mred }}^{0}-0.06 \mathrm{pH}+\frac{0.06}{2} \lg \frac{C_{\mathrm{E}, \text { Mox }}}{C_{\mathrm{E}, \text { Mred }}}\right)
\end{aligned}
$$

\subsubsection{Bulk liquid mass balances}

With the rates of reaction defined by Eqs. 4 and 5, and assuming a batch operation of the MFC with constant anode liquid volume $V_{\mathrm{B}}$, the mass balances for soluble components in the bulk liquid and the corresponding initial conditions are:

$\frac{\mathrm{d} C_{\mathrm{B}, \mathrm{S}}}{\mathrm{d} t}=r_{\mathrm{B}, \mathrm{S}},\left.\quad C_{\mathrm{B}, \mathrm{S}}\right|_{t=0}=C_{0, \mathrm{~S}}$

$\frac{\mathrm{d} C_{\mathrm{B}, \mathrm{Mox}}}{\mathrm{d} t}=r_{\mathrm{B}, \mathrm{Mox}}+r_{\mathrm{E}, \mathrm{Mox}} \frac{A_{\mathrm{E}}}{V_{\mathrm{B}}},\left.\quad C_{\mathrm{B}, \operatorname{Mox}}\right|_{t=0}=C_{0, \text { Mox }}$

$\frac{\mathrm{d} C_{\mathrm{B}, \mathrm{Mred}}}{\mathrm{d} t}=r_{\mathrm{B}, \mathrm{Mred}}+r_{\mathrm{E}, \mathrm{Mred}} \frac{A_{\mathrm{E}}}{V_{\mathrm{B}}},\left.C_{\mathrm{B}, \mathrm{M} \rho \varepsilon \delta}\right|_{t=0}=C_{0, \mathrm{Mred}}$

\subsubsection{Diffusion layer}

Due to mass transfer rate limitations in the boundary layer adjacent to the electrode surface, the concentrations $C_{E}$ needed to calculate the rates (5) are different from those in the bulk liquid, $C_{B}$. Because in this study one assumes no biofilm on the anode, concentrations $C_{E}$ are calculated from a steady-state one-dimensional mass balance equation applied in the MTBL, with diffusion and reactions depending on the local concentrations in the MTBL, $C_{L}$ :

$D_{\mathrm{S}} \frac{\mathrm{d}^{2} C_{\mathrm{L}, \mathrm{S}}}{\mathrm{d} z^{2}}+r_{\mathrm{L}, \mathrm{S}}=0,\left.\quad C_{\mathrm{L}, \mathrm{S}}\right|_{z=L_{\mathrm{L}}}=C_{\mathrm{B}, \mathrm{S}},\left.\quad \frac{\mathrm{d} C_{\mathrm{L}, \mathrm{S}}}{\mathrm{d} z}\right|_{z=0}=0$

$$
\begin{aligned}
& D_{\text {Mred }} \frac{d^{2} C_{\mathrm{L}, \text { Mred }}}{\mathrm{d} z^{2}}+r_{\mathrm{L}, \text { Mred }}=0,\left.\quad C_{\mathrm{L}, \mathrm{Mred}}\right|_{z=L_{\mathrm{L}}}=C_{\mathrm{B}, \text { Mred }} \\
& \left.D_{\text {Mred }} \frac{\mathrm{d} C_{\mathrm{L}, \mathrm{Mred}}}{\mathrm{d} z}\right|_{z=0}+r_{\mathrm{E}, \text { Mred }}=0 \\
& D_{\mathrm{Mox}} \frac{\mathrm{d} C_{\mathrm{L}, \mathrm{Mox}}}{\mathrm{d} z^{2}} r_{\mathrm{L}, \text { Mox }}=0,\left.\quad C_{\mathrm{L}, \mathrm{Mox}}\right|_{z=L_{\mathrm{L}}}=C_{\mathrm{B}, \text { Mox }} \\
& \left.D_{\mathrm{Mox}} \frac{\mathrm{d} C_{\mathrm{L}, \mathrm{Mox}}}{\mathrm{d} z}\right|_{z=0}+{ }_{\mathrm{E}, \mathrm{Mox}}=0
\end{aligned}
$$

One boundary condition reflects the fact that, at a distance from the electrode equal to the diffusion layer thickness $\left(z=L_{\mathrm{L}}\right)$, the concentration is that of the bulk. The other condition expresses the fact that in the steady state the reaction rate at the electrode surface $(z=0)$ must be equal to the diffusion rate. Thus, at $z=0, C_{\mathrm{L}}=C_{\mathrm{E}}$.

\subsubsection{Current and charge}

If uniform current density, $i$, is assumed over the whole electrode surface, the cell current at a moment in time is proportional with the electrode area $A_{\mathrm{E}}$ :

$I=i A_{E}$

The problem is however complicated by the fact that Eq. 18 is implicit in I: i.e., the current density given by the Butler-Volmer Eq. 6 is a function of activation overpotential, which depends in turn on the current $I$ (see Eq. 11). 
The charge $Q_{C}$ (Coulombs) produced is calculated from the integration of cell current over time. The coulombic yield $\left(Y_{\mathrm{Q}}\right)$ is the ratio between the actual charge produced $Q_{\mathrm{C}}$ and the maximum theoretical one, $Q_{\mathrm{C}, \max }$, which is the number of electrons $(\gamma)$ available for a redox reaction in all oxidizable substrates $\left(n_{S}\right.$ moles) fed to the fuel cell:

$Y_{\mathrm{Q}}=\frac{Q_{\mathrm{C}}}{Q_{\mathrm{C}, \max }}=\frac{Q_{C}}{\sum_{i} \gamma_{i} n_{S i}}$

\subsection{Model solution}

The model equations were solved with a reduced onedimensional version of the general algorithm and numerical methods presented in Picioreanu et al. [15] for MFC with biofilms attached on anode. The set of stiff ordinary differential equations (ODE) (12)-(14) are solved for $C_{B}$ between time $t_{n}$ and $t_{n}+\Delta t$ with an implicit method with variable time step [18]. While updated $C_{\mathrm{B}}$ are used at each intermediate time point between $t_{\mathrm{n}}$ and $t_{\mathrm{n}}+\Delta t$, the concentrations $C_{L}$ in MTBL at time $t_{n}$ only are used to calculate the rates $r_{\mathrm{L}}$ and $C_{\mathrm{E}}$ to calculate $r_{\mathrm{E}}$. A multigrid method for non-linear systems of elliptic PDEs is used for equations (15)-(17) [18]. Because the current calculation involves an implicit equation in $I$, the solution $\left[C_{B}, C_{L}(z), C_{E}\right]$ at each moment in time is recalculated until a root-finding algorithm (Brent's method from [18] converges to a current $I$ satisfying Eq. 18 .

\section{Results and discussion}

The case proposed to illustrate the model simulates the current-time evolution in a simple microbial fuel cell with one soluble mediator and one type of suspended cell only, operated in a batch mode fed with one type of substrate. This set-up permits a straightforward quantitative evaluation based on experimental data obtained in well-defined conditions (e.g., [5]. This model evaluation serves as basis for a more complete model assessment of the MFC functioning when a heterogeneous multispecies biofilm is present on the anode, as presented in Picioreanu et al. [15].

\subsection{Estimation of model parameters}

In order to compare quantitatively the model results with the measured current and potential values from Delaney et al. [5], several model parameters have to be estimated. The MFC geometry (anode space volume, anode area), the operational conditions $(\mathrm{pH}$, biomass concentration, initial substrate and mediator concentrations) and electrical parameters (external resistance, cathode potential) were directly taken from in Delaney et al. [5]. Some kinetic parameters, such as the rate constant for microbial reduction of thionine and its standard potential were determined in a complementary study by Roller et al. [21].

A series of unknown parameters had to be extracted from the experimental data. First, the real substrate yield $Y_{\mathrm{S}}$ and coulombic yield $Y_{\mathrm{Q}}$ are estimated by fitting the current-time and charge-time measured curves, as shown in Fig. 3b. The total charge finally obtained in the MFC comes from both substrate and mediator oxidation. From Faraday's law applied in the ideal case when all glucose electrons are converted into current $\left(Q_{\mathrm{C}, \mathrm{S}}=C_{0, \mathrm{~S}} V_{\mathrm{B}} n F\right), 23.16 \mathrm{C}$ would be produced from the substrate (assumed as glucose with

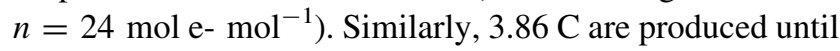
the end of experiment from the reduced mediator (assumed as thionine with $n=2 \mathrm{~mol} \mathrm{e}-\mathrm{mol}^{-1}$ ), thus in total 27.01 Coulombs. This charge amount is indeed obtained in the simulations with a glucose per mediator yield $Y_{\mathrm{S}}=0.0833 \mathrm{~mol} \mathrm{~mol}^{-1}$ (i.e., $Y_{\mathrm{Q}}=1$ ) (Fig. 4). In reality, by integration of current-time curves from Delaney et al. [5], one obtains $12.6 \mathrm{C}$ in total, which means only $8.74 \mathrm{C}$ from glucose. This represents $Y_{\mathrm{Q}}=0.37$, and a real glucose per mediator yield of $Y_{\mathrm{S}}=0.22 \mathrm{~mol} \cdot \mathrm{mol}^{-1}$. These values allow a good fitting of the current-time and charge-time
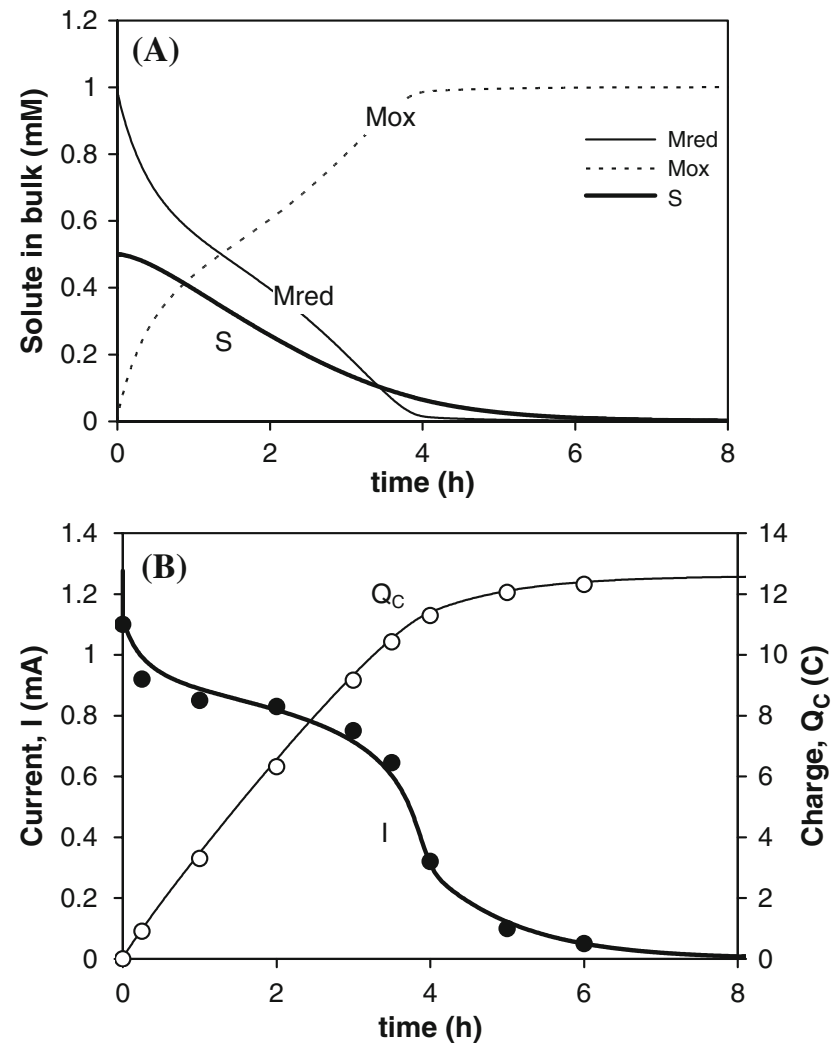

Fig. 3 Simulation results in standard case conditions (Table 1). a Time course of soluble components concentrations in bulk liquid, $C_{\mathrm{B}, \mathrm{S}}, C_{\mathrm{B}, \text { Mred }}$, and $C_{\mathrm{B}, \mathrm{Mox}}$ (in $\mathrm{mM}$ ). b Time course of current $(I, \mathrm{~mA})$ - thick line: simulation results; black circles: experimental data from [5] - and charge produced $\left(Q_{\mathrm{C}}, \mathrm{C}\right)$ - thin line: simulation results; open circles: experimental data from [5] 


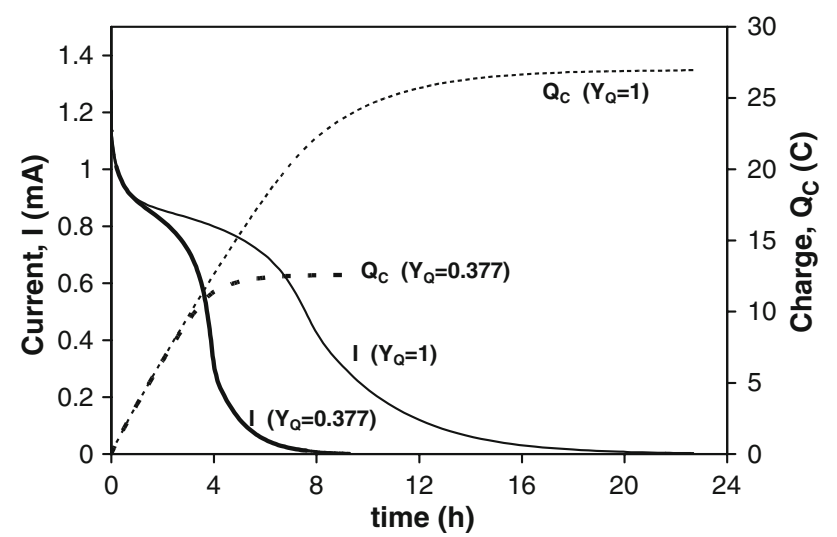

Fig. 4 Simulated current (solid lines) and total charge (dashed lines) production in time at maximum coulombic yield $\left(Y_{\mathrm{Q}}=1\right)$ for which the glucose per mediator yield is $Y_{\mathrm{S}}=0.0833 \mathrm{~mol} \mathrm{~mol}^{-1}$ (thin lines) and in the conditions matching the currents obtained experimentally by Delaney et al. [5], i.e., at a coulombic yield $Y_{\mathrm{Q}}=0.377$ when the glucose per mediator yield is $Y_{\mathrm{S}}=0.22 \mathrm{~mol} \mathrm{~mol}^{-1}$ (thick lines)

experimental values (Fig. 3b), because less current is actually produced per mol glucose than in the ideal case (Fig. 4).

Furthermore, the MFC experimental current-voltage curves determined by Delaney et al. [5] using thionine and Proteus vulgaris were used to determine the mass transfer parameters for mediator and the exchange current $i_{0, \text { ref }}$. Higher exchange currents would shift the $V_{\text {cell }}-I$ curve to higher values (Fig. 5a). An acceptable value found was in the range of $10^{-3} \mathrm{~A} \mathrm{~m}^{-2}$. The rate of mediator mass transfer to anode will then determine the limiting current, which in this case is about $25 \mathrm{~mA}$. Higher mass transfer resistance (i.e., thicker diffusion layer $L_{\mathrm{L}}$ or lower diffusion coefficients $D_{\text {Mred }}=D_{\text {Mox }}=D$ ) would decrease the limiting current (Fig. 5a) and the power produced (Fig. 5b). A good description of the limiting current is obtained with $L_{\mathrm{L}}=50 \mu \mathrm{m}$ and $D=9 \times 10^{-6} \mathrm{~m}^{2} \mathrm{day}^{-1}$, which means a mass transfer coefficient $k=D / L_{\mathrm{L}}=0.2 \mathrm{~m} \mathrm{day}^{-1}=2 \times 10^{-6} \mathrm{~m} \mathrm{~s}^{-1}$.

Finally, the Monod half-saturation coefficients for substrate and oxidized mediator will mainly affect the currenttime curves when these compounds reach low values (i.e., $C_{\mathrm{S}} \ll K_{\mathrm{S}}$ and $\left.C_{\mathrm{Mox}} \ll K_{\mathrm{Mox}}\right)$. For example, a high $K_{\mathrm{S}}$ will slow down the microbial process, thus lowering the current produced but extending the tail that appears after $4 \mathrm{~h}$. Because the coulombic yield is unaffected, a smaller current is produced over longer time intervals. All parameter values used in the standard case simulation are listed in Table 1, and the results presented in Fig. 3.

\subsection{Simulated cases}

The aim of these simulations is the investigation of the effect of various MFC operational parameters on the current production and on substrate consumption in time. Subsequently, different simulations were performed changing:
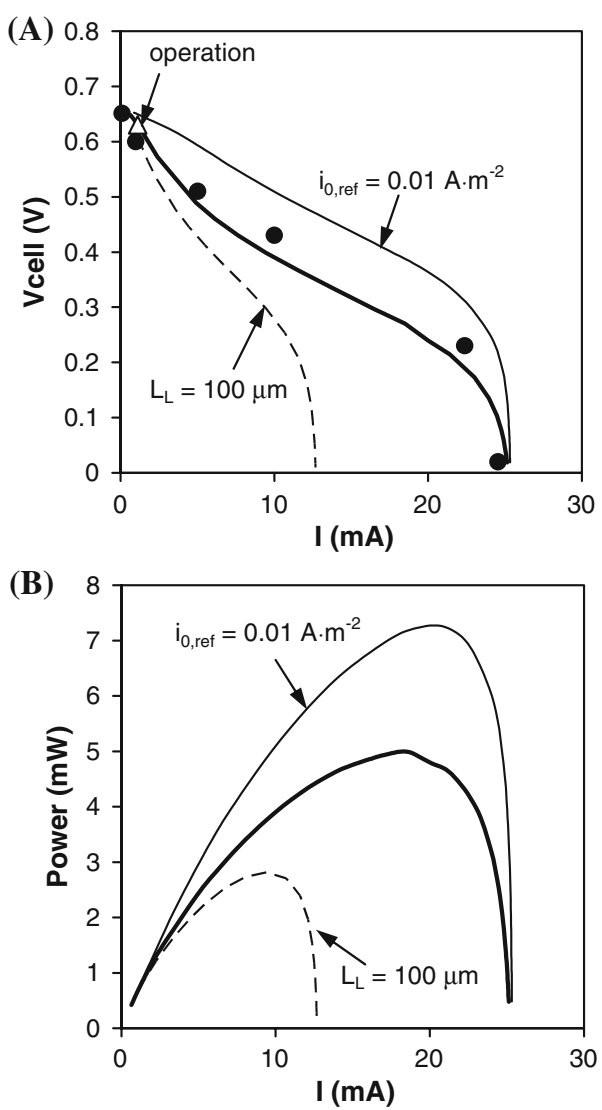

Fig. 5 Simulated current-voltage (a) and power (b) curves for the MFC operated in the standard conditions $\left(L_{\mathrm{L}}=50 \mu \mathrm{m}\right.$, $i_{0, \text { ref }}=0.001 \mathrm{~A} \mathrm{~m}^{-2}$, thick solid lines $)$, for a higher exchange current $\left(i_{0, \text { ref }}=0.01 \mathrm{~A} \mathrm{~m}^{-2}\right.$, thin solid lines $)$, and for a larger resistance to mass transfer $\left(L_{\mathrm{L}}=100 \mu \mathrm{m}\right.$, thin dashed lines $)$. The experimental points on the current-voltage curves (a) are from Delaney et al. [5]

(A) biomass concentration to 750 and $3000 \mathrm{~g} \mathrm{~m}^{-3}$ (Fig. 6a); (B) initial glucose concentration to 0.25 and $1.0 \mathrm{M}$ (Fig. 6b); (C) initial mediator concentrations to 0.1:0.001 $\mathrm{mM}$ and 0.001:1 mM reduced: oxidized forms (Fig. 6c); (D) mass transfer boundary layer thickness for the mediator to 25 and $400 \mu \mathrm{m}$ (Fig. 6d); (E) total cell resistance to 100 and $1000 \Omega$ (Fig. 6e).

\subsubsection{Standard case}

In the standard case, the system contains initially the mediator in the reduced form. Consequently, the current quickly falls to a slightly decreasing plateau value, resulting from the balance between the rates of mediator oxidation at the anode and reduction by the microorganisms (Fig. 3b). This trend is observed in all experimental studies where the MFC is discharged after a period of operation at open circuit, when endogenous metabolism of cells prior the experiment establishes a high initial ratio between reduced and oxidized mediator [5, 24]. The plateau phase cannot be sustained after the substrate is consumed (or reaches values much lower 
Table 1 Model parameters for the standard case simulation with suspended cells and mediator in the anodic chamber of a MFC

\begin{tabular}{|c|c|c|c|c|}
\hline Parameter & Description & Value & Units & Source \\
\hline$C_{0, \mathrm{~s}}$ & Initial concentration substrate (glucose) & 0.5 & $\mathrm{mM}$ & Delaney et al. [5] \\
\hline$C_{0, \text { Mred }}$ & Initial concentration reduced mediator & 1 & $\mathrm{mM}$ & Delaney et al. [5] \\
\hline$C_{0, \text { Mox }}$ & Initial concentration oxidized mediator & $10^{-3}$ & $\mathrm{mM}$ & Assumed \\
\hline$C_{\mathrm{X}}$ & Biomass concentration in bulk liquid & 1500 & $\mathrm{~g} \mathrm{~m}^{-3}$ & Delaney et al. [5] \\
\hline $\mathrm{pH}$ & & 7 & & Delaney et al. [5] \\
\hline$D_{\text {Mred }}, D_{\text {Mox }}$ & Diffusion coefficient mediator & $9 \times 10^{-6}$ & $\mathrm{~m}^{2} \mathrm{day}^{-1}$ & $\begin{array}{l}\text { Estimated from current-voltage } \\
\text { curves from Delaney et al. [5] }\end{array}$ \\
\hline$D_{\mathrm{S}}$ & Diffusion coefficient glucose & $1 \times 10^{-4}$ & $\mathrm{~m}^{2}$ day $^{-1}$ & Wanner et al. [25] \\
\hline$L_{\mathrm{L}}$ & $\begin{array}{l}\text { Mass transfer boundary layer thickness } \\
\text { for mediator at the anode }\end{array}$ & 50 & $\mu \mathrm{m}$ & Same as for diffusion coefficients \\
\hline$V_{\mathrm{B}}$ & Bulk liquid volume & $2 \times 10^{-5}$ & $\mathrm{~m}^{3}$ & Delaney et al. [5] \\
\hline$A_{\mathrm{F}}$ & Anode surface area & 0.08 & $\mathrm{~m}^{2}$ & Delaney et al. [5] \\
\hline$V_{\mathrm{C}}$ & Cathode potential & 0.68 & $\mathrm{~V}$ & $\begin{array}{l}\text { Assumed for ferricyanide cf. } \\
\text { Delaney et al. [5] }\end{array}$ \\
\hline$R_{\mathrm{int}}+R_{\mathrm{ext}}$ & Total cell resistance & 560 & $\Omega$ & Delaney et al. [5] \\
\hline$i_{0, \text { ref }}$ & $\begin{array}{l}\text { Exchange current density for mediator } \\
\text { oxidation in reference conditions } \\
\left(S_{\text {ref,Mred }}=S_{\text {ref,Mox }}=1 \mathrm{mM}\right)\end{array}$ & 0.001 & $\mathrm{~A} \mathrm{~m}^{-2}$ & $\begin{array}{l}\text { Estimated from current-voltage curves } \\
\text { from Delaney et al. [5] }\end{array}$ \\
\hline$E_{\mathrm{Mox} / \mathrm{Mred}}^{0}$ & $\begin{array}{l}\text { Standard reduction potential for the } \\
\text { mediator couple (vs. SHE) }\end{array}$ & 0.477 & $\mathrm{~V}$ & $\begin{array}{l}\text { assumed for thionine cf. } \\
\text { Roller et al. [21] }\end{array}$ \\
\hline$b$ & Tafel coefficient for mediator oxidation & 0.120 & $\mathrm{~V}$ & Assumed for two-electron reaction \\
\hline$k_{1}$ & $\begin{array}{l}\text { Maximum specific rate constant for } \\
\text { microbial reduction of mediator }\end{array}$ & $2 \times 10^{-4}$ & $\begin{array}{l}\text { (kmol mediator }) \\
\quad(\mathrm{g} \text { biomass })^{-1} \text { day }^{-1}\end{array}$ & Roller et al. [21] \\
\hline$Y_{\mathrm{S}}$ & $\begin{array}{l}\text { Yield in mol substrate converted } \\
\text { per mol mediator }\end{array}$ & 0.22 & $\begin{array}{l}(\mathrm{mol} \mathrm{S}) \\
\quad(\mathrm{mol} \mathrm{Med})^{-1}\end{array}$ & $\begin{array}{l}\text { Estimated from the coulombic } \\
\text { yield from Delaney et al. [5] }\end{array}$ \\
\hline$K_{\mathrm{S}}$ & $\begin{array}{l}\text { Monod half-saturation coefficient } \\
\text { for substrate }\end{array}$ & 1 & $\mathrm{mM}$ & $\begin{array}{l}\text { Estimated from current evolution from } \\
\text { Delaney et al. [5] }\end{array}$ \\
\hline$K_{\text {Mox }}$ & $\begin{array}{l}\text { Monod half-saturation coefficient } \\
\text { for oxidized mediator }\end{array}$ & 2 & $\mathrm{mM}$ & $\begin{array}{l}\text { Estimated from current evolution from } \\
\text { Delaney et al. [5] }\end{array}$ \\
\hline$k_{2}$ & $\begin{array}{l}\text { Maximum specific rate coefficient for: } \\
\text { (1) endogenous metabolism } \\
\text { (2) storage polymer oxidation }\end{array}$ & $\begin{array}{l}2 \times 10^{-6} \\
2 \times 10^{-5}\end{array}$ & $\begin{array}{l}\text { (kmol mediator }) \\
\quad(\mathrm{g} \text { biomass })^{-1} \text { day }^{-1}\end{array}$ & $\begin{array}{l}\text { Estimated from background } \\
\text { current in Delaney et al. [5] }\end{array}$ \\
\hline$Y_{\mathrm{P}}$ & $\begin{array}{l}\text { Yield in mol poly-substrate formed } \\
\text { per mol mediator }\end{array}$ & 0.04 & $(\mathrm{~mol}$ polyS $)(\mathrm{mol} \mathrm{Med})^{-1}$ & $\begin{array}{l}\text { Estimated from background current } \\
\text { in Delaney et al. [5] }\end{array}$ \\
\hline
\end{tabular}

The parameters $k_{2}$ and $Y_{\mathrm{P}}$ are needed only to describe the background current due to endogenous metabolism or to stored intracellular substrate

than $K_{\mathrm{S}}$ ) in about $4 \mathrm{~h}$ (Fig. 3a). Accordingly, the produced current quickly decreases after this time (Fig. 3b), because the oxidized mediator cannot be further reduced.

\subsubsection{Initial biomass and substrate concentrations}

An increasing biomass concentration in the MFC results in higher currents (Fig. 6a1), as the microorganisms will produce more reduced mediator which is available for the electrochemical oxidation. At the same time, however, because substrate is consumed faster (Figure 6a2), the plateau current can be maintained for shorter periods. If no biomass is added, this will lead to fast $(\sim 1 \mathrm{~h})$ mediator oxidation associated with a rapid fall of current (Fig. 6a1). Increasing the initial concentrations of substrate ("fuel") will, as expected, make the plateau current last longer (Fig. 6b), but the current is not higher because biomass is still limiting. No substrate inhibition or multiple substrate conversion pathways have been considered here, but this may be the case in actual MFC operation.

\subsubsection{Initial redox state of mediator}

Although in the MFC experiments of Bennetto's group [5, $21,24]$ the current falls quickly after closing the MFC electrical circuit, other groups actually report a fast increase in current [11] in a similar MFC arrangement. This can be explained by starting the experiment with the mediator in the oxidized form (Fig. 6c). Consequently, a period of time of a few minutes is needed for the 
Fig. 6 Sensitivity evaluation for several parameters in the MFC model on: (a1, b-e) current production $(I, \mathrm{~mA})$ and (a2) glucose concentration $\left(C_{\mathrm{B}, \mathrm{S}}, \mathrm{mM}\right)$. The parameters varied are: a suspended biomass concentration $C_{\mathrm{X}} ; \mathbf{b}$ initial glucose concentration $C_{0, \mathrm{~s}}$; c initial mediator concentration and the ratio between the reduced and oxidized forms, $C_{0, \text { Mred }}$, and $C_{0, \text { Mox }} ; \mathbf{d}$ mass transfer boundary layer thickness, $L_{\mathrm{L}}$; e external ohmic resistance, $R_{\text {ext }}$
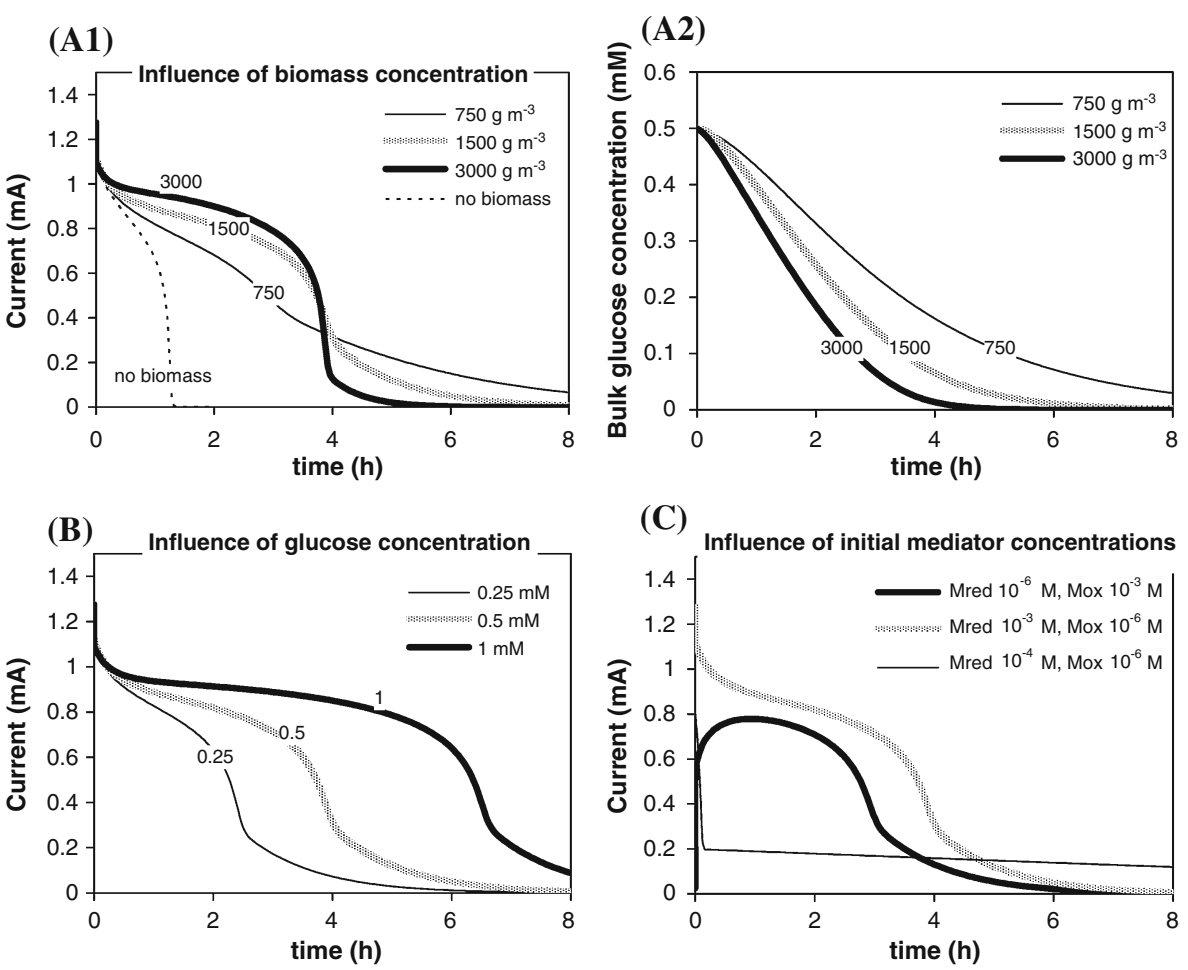

(D)

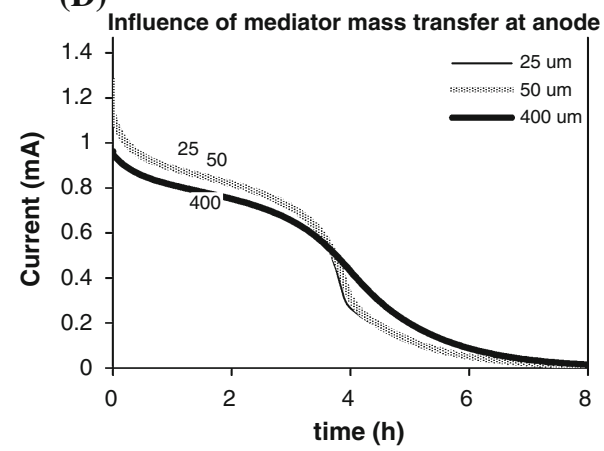

(E)

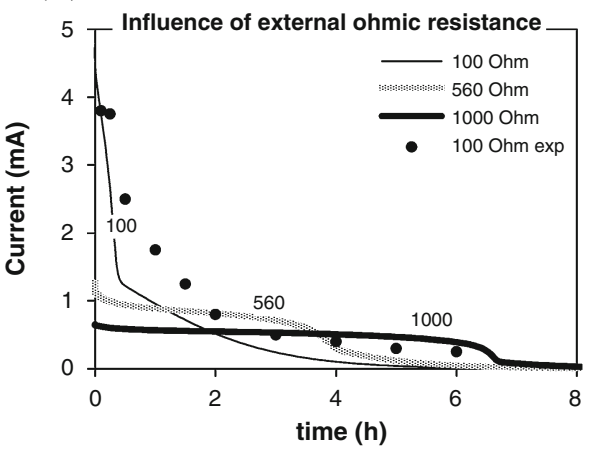

microorganisms to produce the reduced mediator which will generate the anodic current. When lower mediator concentrations are used $(0.1 \mathrm{mM})$ the current produced is, of course, lower, but it stays remarkably constant for longer periods of time (Fig. 6c). This is because the substrate oxidation is now restricted by the availability of the oxidized mediator, whose production at the anode is limited by mediator mass transfer.

\subsubsection{Mass transfer rate at the anode}

The mediator mass transfer at the anode surface was further investigated by varying the MTBL thickness (Fig. 6d). Better mixing in the anode compartment leads to a thinner MTBL (e.g., 25 and $50 \mu \mathrm{m}$ vs. $400 \mu \mathrm{m}$ ), and therefore to increased currents. However, in this particular case, the decrease in the current produced at thicker MTBL (e.g., 400 $\mu \mathrm{m})$ is still not very pronounced. This is expected because, under the standard conditions chosen, the MFC does not function in a mass transfer limited regime. It can be seen easily on the voltage-current curve from Fig. 5a that the operation point marked with a triangle indicates a kinetic limitation (mass transfer limitation is only at the highest currents). The other fuel cell performance indicator, the power produced at different operating currents $\left(P=V_{\text {cell }} I\right)$, is calculated and presented in Fig. 5b. It is clear that the MFC in the standard case from Delaney et al. [5] operates far from the power peak, at currents around only $1 \mathrm{~mA}$.

\subsubsection{Electrical circuit resistance}

To illustrate the effect of the electrical resistance through which the MFC is discharged, further simulations were performed. As expected, higher resistance leads to lower currents extended over longer time periods (Fig. 6e). According to Eq. 11 a lower external resistance decreases the total 
ohmic contribution to potential loss and thus increases the driving force $\eta_{\mathrm{A} \text {,act }}$ for the rate of anodic mediator oxidation. However, because the anodic oxidation of mediator runs faster at $100 \Omega$, the microbial conversion of substrate will be so much enhanced that the substrate becomes quickly depleted and the plateau phase can hardly be distinguished. Qualitatively, this compares well (see Fig. 6e) with the experimental data obtained by Delaney et al. [5].

\subsubsection{Repeated substrate addition}

Repeated addition of glucose in pulses of $0.5 \mathrm{mM}$ after its exhaustion leads to a regeneration of current output to the same "steady" levels, as shown in Fig. 7. However, as it was also experimentally observed by Delaney et al. [5], in reaching the quasi-steady state the current evolution in time follows different patterns after subsequent substrate pulses compared with the beginning of the experiment
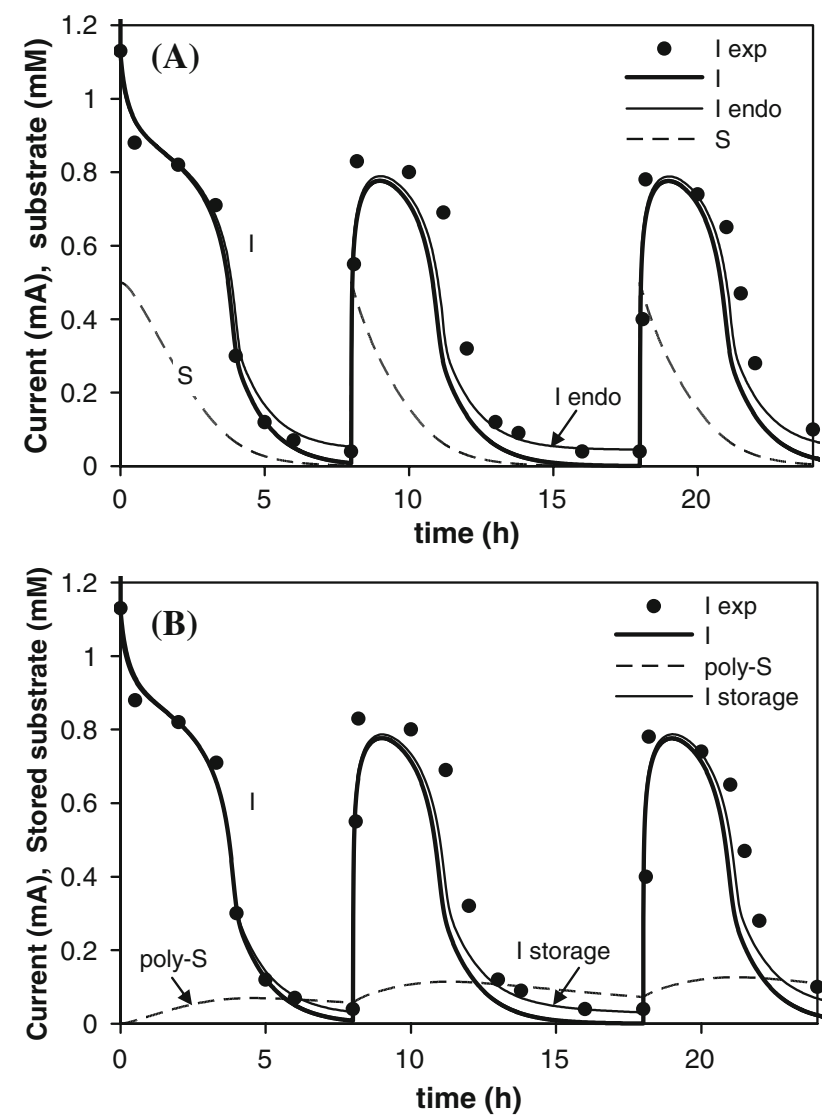

Fig. 7 Simulated variation of current output $(I, \mathrm{~mA})$ with time on repeated additions of substrate at 0,8 and $18 \mathrm{~h}$. Thick black lines: current production with all parameters as in the standard case. Thin black lines: a current production when an endogenous reaction takes place, $\mathbf{b}$ current production when storage of substrate as intracellular polymers is assumed. Dashed lines: a glucose concentration in bulk liquid $\left(C_{\mathrm{B}, \mathrm{S}}, \mathrm{mM}\right)$, b concentration of intracellular stored substrate (poly-S) per bulk liquid $(\mathrm{mM})$, The black circles are the experimental data measured by Delaney et al. [5] (experimental points also shown in Fig. 7). The decreasing trend at the beginning, as opposed to the increase in current output following later substrate pulses, is due to the dominant form in which the mediator exists at the moment when substrate is added. Initially, almost all the mediator is reduced, leading to higher initial currents. Conversely, at later substrate additions the mediator is already oxidized, which requires some time for its microbial reduction.

\subsubsection{Background current and endogenous metabolism}

In the experiments by Delaney et al. [5] and Kim et al. [11] it was consistently observed that after the added substrate is depleted the current falls to a non-zero value. This background current can be produced if the microorganisms continue to reduce the mediator by using other available substrates. The simplest way to model this background current is by assuming endogenous metabolism consuming part of the biomass component while reducing the mediator. This is the standard method in activated sludge models [8]. A second related possibility is to assume that in the absence of the main electron donor (substrate) bacteria use internal reserves of substrate such as storage polymers (e.g., glycogen, polyhydroxyalkanoates, etc. [2]. Another possibility involves the slower degradation of different metabolic intermediates produced in the metabolism of the added substrate [24]. All three possibilities were examined by model simulations and found to produce similar results.

The simulated current output shown in Fig. 7a occurs when an additional endogenous process takes place besides the main substrate oxidation reaction. In the additional reaction, oxidized mediator and biomass are reactants and reduced mediator is produced

$Y_{\text {endo }} \mathrm{X}+\mathrm{M}_{\mathrm{ox}} \rightarrow \mathrm{M}_{\mathrm{red}}+$ products

with a Monod kinetics in Mox $\left(K_{\mathrm{Mox}}=2 \mathrm{mM}\right)$ and a maximum rate constant $k_{2}=2 \times 10^{-6} \quad((\mathrm{kmol}$ mediator) $\left.(\mathrm{g} \text { biomass })^{-1} \mathrm{day}^{-1}\right)$ :

$r_{2}=k_{2} C_{\mathrm{X}} \frac{C_{\mathrm{Mox}}}{K_{\mathrm{Mox}}+C_{\mathrm{Mox}}}$

As expected, simulations showed that the higher the rate of the endogenous process the higher the level of background current. From Fig. $7 \mathrm{a}$ it is clear that this mechanism gives a better agreement with the measurements of Delaney et al. [5]. Moreover, if more biomass is consumed in the endogenous reaction than it is formed by growth, the peak current will gradually decrease following subsequent substrate additions.

Alternatively, it becomes clear from Fig. 7b that very similar results can be obtained when substrate is also stored in intra-cellular polymers ("poly-S" with an yield $Y_{\mathrm{P}}=$ $0.04 \mathrm{~mol} \mathrm{~mol}^{-1}$ in Eq. 22) 
$Y_{\mathrm{S}} \mathrm{S}+\mathrm{M}_{\mathrm{ox}} \rightarrow \mathrm{M}_{\mathrm{red}}+Y_{\mathrm{P}}$ polyS + products

concomitantly with the oxidation of stored polymer with mediator

$Y_{\mathrm{S}}$ polyS $+\mathrm{M}_{\mathrm{ox}} \rightarrow \mathrm{M}_{\mathrm{red}}+$ products

This approach would require estimation of more parameters than that for the endogenous metabolism. However, for simplicity, the oxidation of storage polymers (Eq. 23) can be described by the same stoichiometry and rate parameters as the substrate conversion (Eq. 22):

$r_{2}=k_{2} C_{\mathrm{X}} \frac{C_{\mathrm{polyS}}}{K_{\mathrm{S}}+C_{\mathrm{polys}}} \frac{C_{\mathrm{Mox}}}{K_{\mathrm{Mox}}+C_{\mathrm{Mox}}}$

with the only difference that the rate coefficient $k_{2}$ must be 10 times slower than $k_{1}$ in order to describe the slow production of a residual current after the external substrate has been exhausted $\left(k_{2}=2 \times 10^{-5}\right.$ (kmol mediator) $(\mathrm{g} \text { biomass })^{-1}$ day $\left.^{-1}\right)$.

The slower degradation of metabolic intermediates can be represented by a mechanism exactly similar to that for substrate storage. A more detailed analogue of this case would be fast glucose conversion to organic acids (e.g., pyruvic, lactic, propionic, acetic) and glycerol, followed by the slower transformation of these intermediates [24]. When this chain of reactions occurs in separate specialized microorganisms it is called anaerobic digestion and its implications in biofilm-based microbial fuel cells have been modelled in Picioreanu et al. [16] and Picioreanu et al. [17].

\section{Conclusions}

The computational model brings together in a rigorous though flexible computational framework the most important biological, chemical and physical processes occurring in MFCs with suspended cells and diffusible electron transfer mediator. The modelled cases presented in this article show that the model accurately describes the behaviour of the MFC functioning in batch or fed-batch mode. Current production in time, as well as voltage-current characteristics could be correctly computed when tested against the experimental data obtained in similar MFC setups by Delaney et al. [5]. Moreover, the model calibrated on one set of data could reasonably predict results obtained in other experimental conditions. Simulations readily show the effect of different operational parameters on the MFC characteristics. All of these, and the results presented in a companion paper for the biofilm-based MFC [15], encourage the model application in more complex cases involving multiple substrates and mixed microbial communities, such as in MFCs designed to function on wastewater-based influents.
Acknowledgements This research was supported by the European Union through Marie Curie Transfer of Knowledge fellowships to Cristian Picioreanu and Krishna Katuri (contract MTKD-CT-2004517215).

\section{References}

1. Bennetto HP, Dew ME, Stirling JL, Tanaka K (1981) Rates of reduction of phenothiazine 'redox' dyes by E. coli. Chem Ind 7: 776-778

2. Beun JJ, Van Loosdrecht MCM, Heijnen JJ (2001) N-removal in a granular sludge sequencing batch airlift reactor. Biotechnol Bioeng 75(1):82-92

3. Bullen RA, Arnot TC, Lakemanc JB, Walsh FC (2005) Biofuel cells and their development. Biosens Bioelectron 21(11):20152045

4. Chang IS, Moon H, Bretschger O, Jang JK, Park HI, Nealson KH, Kim BH (2006) Electrochemically active bacteria (EAB) and mediator-less microbial fuel cells. J Microbiol Biotechnol 16(2): 163-177

5. Delaney GM, Bennetto HP, Mason JR, Roller SD, Stirling JL, Thurston CF (1984) Electron-transfer coupling in microbial fuel cell. 2. Performance of fuel cells containing selected microorganisms-mediator-substrate combination. J Chem Technol Biotechnol 34B:13-27

6. Fuel cell handbook (2004) 7th edn. E.G\&G Technical Services, Parsons, Inc. for the National Energy Technology Laboratory, www.netl.doe.gov/seca/pubs/FCHandbook7.pdf

7. Heijnen JJ (1999) Bioenergetics of microbial growth. In: Flickinger MC, Drew SW (eds) Encyclopedia of bioprocess technology: fermentation, biocatalysis, bioseparation. WileyInterscience, New York, pp 267-291

8. Henze, M., Gujer, W., Mino, T. and Van Loosdrecht, M.C.M. (2000) Activated sludge models ASM1, ASM2, ASM2d and ASM3. IWA Scientific \& Technical Report, IWA Publishing, London, UK

9. Kato-Marcus A, Torres CI, Rittmann BE (2007) Conductionbased modeling of the biofilm anode of a microbial fuel cell. Biotechnol Bioeng 98:1171-1182

10. Katz E, Shipway AN, Wilner I (2003) Biochemical fuel cells. In: Vielstich W, Lamm A, Gasteiger HA (eds) Handook of fuel cellsfundamentals, technology, application. Wiley, Chichester, pp 355-381

11. Kim N, Choi Y, Jung S, Kim S (2000) Effect of initial carbon sources on the performance of microbial fuel cells containing Proteus vulgaris. Biotechnol Bioeng 70:109-114

12. Logan BE, Hamelers B, Rozendal R, Schröder U, Keller J, Freguia S, Aelterman P, Verstraete W, Rabaey K (2006) Microbial fuel cells: methodology and technology. Environ Sci Technol 40(17):5181-5192

13. Lovley DR (2006) Bug juice: harvesting electricity with microorganisms. Nat Rev Microbiol 4:497-508

14. Newman JS (1991) Electrochemical systems, 2nd edn. Prentice Hall, Englewood Cliffs, NJ

15. Picioreanu C, Head IM, Katuri KP, Van Loosdrecht MCM, Scott K (2007) A computational model for biofilm-based microbial fuel cells. Water Res 41(13):2921-2940

16. Picioreanu C, Katuri KP, Head IM, Van Loosdrecht MCM, Scott K (2008) Mathematical model for microbial fuel cells with anodic biofilms and anaerobic digestion. Water Sci Technol 57(7):965-971

17. Picioreanu C, Van Loosdrecht MCM, Curtis TP, Scott K (2009) Model based evaluation of the effect of $\mathrm{pH}$ and electrode geometry on microbial fuel cell performance. Bioelectrochemistry (in press). doi:10.1016/j.bioelechem.2009.04.009 
18. Press WH, Teukolsky SA, Vetterling WT, Flannery BP (1997) Numerical recipes in $\mathrm{C}$ : the art of scientific computing. Cambridge University Press, NY

19. Rabaey K, Lissens G, Verstraete W (2005) Microbial fuel cells: performances and perspectives. In: Lens PN, Westermann P, Haberbauer M, Moreno A (eds) Biofuels for fuel cells: biomass fermentation towards usage in fuel cells. IWA Publishing, London

20. Rabaey K, Verstraete W (2005) Microbial fuel cells: novel biotechnology for energy generation. Trends Biotechnol 6:291-298

21. Roller SD, Bennetto HP, Delaney GM, Mason JR, Stirling JL, Thurston CF (1984) Electron-transfer coupling in microbial fuelcells. 1. Comparison of redox-mediator reduction rates and respiratory rates of bacteria. J Chem Technol Biotechnol B Biotechnol 34:3-12

22. Sakai S, Yagishita T (2007) Microbial production of hydrogen and ethanol from glycerol-containing wastes discharged from a biodiesel fuel production plant in a bioelectrochemical reactor with thionine. Biotechnol Bioeng 98:340-348

23. Shukla AK, Suresh P, Berchmans S, Rahjendran A (2004) Biological fuel cells and their applications. Curr Sci 87:455-468

24. Thurston CF, Bennetto HP, Delaney GM, Mason JR, Roller SD, Stirling JL (1985) Glucose metabolism in a microbial fuel cell. Stoichiometry of product formation in a thionine-mediated Proteus vulgaris fuel cell and its relation to coulombic yields. J Gen Microbiol 131:1393-1401

25. Wanner O, Eberl HJ, Morgenroth E, Noguera DR, Picioreanu C, Rittmann BE, Van Loosdrecht MCM (2006) Mathematical modeling of biofilms. IWA Scientific and Technical Report no. 18, IWA Publishing, UK

26. Zhang X-C, Halme A (1995) Modeling of a microbial fuel cell process. Biotechnol Lett 17:809-814 